\title{
El Dioscórides de Andrés Laguna en los textos de Cervantes: de la materia medicinal al universo literario
}

\author{
FrANCISCO LÓPEZ-MuÑoZ* y CECILIO Álamo*
}

\section{INTRODUCCIÓN}

Una de las aproximaciones más explorada de los textos cervantinos ha sido la vertiente médica. De hecho, diversos autores han incidido en las enseñanzas que estas creaciones literarias nos han legado, permitiendo así ampliar nuestros conocimientos sobre la forma de entender numerosas enfermedades, así como sus remedios, durante el Humanismo tardío en España (López, 1971; Beá y Hernández, 1984; Reverte Coma, 1992; Chiappo, 1994; Osterc, 1996; Peña, 1999; Peleg et al., 2001; Valle, 2002; Alonso-Fernández, 2005; Esteva de Sagrera, 2005; García Barreno, 2005; Montes-Santiago, 2005; Puerto, 2005a; Sánchez Grangel, 2005; Villamil y Villacián; 2005; López-Muñoz et al., 2006a,b).

Sin embargo, entre los numerosísimos aspectos estudiados en relación a los textos cervantinos, y que permitirían hacer una pormenorizada composición de lugar de la formación científica y técnica de Miguel de Cervantes (1547-1616), la medicina es, sin duda, una de las disciplinas más polémicas, en parte debido a la dificultad para determinar los conocimientos médicos del autor del Quijote (López, 1971). En este sentido, existen tres aspectos que han sido resaltados en varias ocasiones y que podrían explicar la exce-

\footnotetext{
*. Departamento de Farmacología, Facultad de Medicina, Universidad de Alcalá.
} 
lente caracterización médica de los protagonistas de las obras de Cervantes: en primer lugar, su estrecha relación familiar con el mundo de la medicina ${ }^{1}$, hecho extrapolable a su círculo de amistades; en segundo lugar, su experiencia militar de juventud, que pudo servirle para conocer algunos remedios terapéuticos susceptibles de elaborarse de manera bastante sencilla con ingredientes de fácil acceso, sobre todo para curar heridas y traumatismos; finalmente, y en tercer lugar, la disponibilidad, no habitual en aquella época entre los cultivadores de la literatura, de una serie de obras técnicas particulares que Cervantes pudo haber consultado de forma reiterada para dotar de mayor realismo y consistencia a sus obras. De hecho, con respecto a la biblioteca cervantina, Eisenberg constató que entre los numerosos libros que Cervantes poseyó, y que alcanzaron los 214 volúmenes, se encontraban varios ejemplares de tratados médicos muy conocidos en su época (Eisenberg, 2002), como el Dioscórides (1555), comentado e ilustrado por Andrés Laguna (1499-1560), y el Examen de ingenios para las ciencias (1575), de Juan Huarte de San Juan (1529-1588).

Estos libros, así como otros que Cervantes pudo leer, aunque no adquirir, bien pudieron servir como fuente médica para que el literato caracterizara a algunos de sus personajes. En concreto, en relación con los textos científicos de naturaleza médica, se ha destacado la posible influencia en la concepción de su personaje más famoso, Don Quijote, de las obras de Huarte de San Juan, el Examen de ingenios para las ciencias (Salillas, 1905; Martín-Araguz y Bustamante-Martínez, 2004), y de Erasmo de Rotterdam (1446-1536), Elogio de la locura (Moriae encomium) (Vilanova, 1949; Bataillon, 1966; Castro, 2002). Para Salillas (1905), el Examen de ingenios para las ciencias influyó decisivamente en la redacción del Quijote, y no sólo en el calificativo de "ingenioso" 2 con el que el literato califica a su protagonista o en la hipótesis sobre la relación entre el exceso de lectura y la locura, sino en más de un aspecto sobre la semblanza de la condición física y mental de Don Quijote, coincidente con los postulados expuestos por Huarte de San Juan en su obra (Martín-Araguz y BustamanteMartínez, 2004; Centro Virtual Cervantes, 2005). De hecho, Cervantes incluso utilizó literalmente en el Quijote varios fragmentos del Examen de ingenios, como recientemente han confirmado Martín-Araguz y BustamanteMartínez (2004). Sin embargo, Cervantes no alude directamente en sus escritos a Huarte de San Juan, posiblemente porque conociese los problemas

1. Es bien conocido que Cervantes procedía de una familia de sanitarios: su bisabuelo Juan Díaz de Torreblanca ( $i^{-1512)}$ era bachiller médico y cirujano con ejercicio en Córdoba, su padre Rodrigo de Cervantes (1509-1585) cirujano-sangrador y su hermana Andrea de Cervantes (1545?-1609) enfermera. En este marco familiar, es muy posible que Cervantes fuese partícipe de ciertas prácticas médicas y curativas, que pudo transfundir a sus creaciones literarias.

2. Este texto, una de las obras científicas de mayor proyección en la Europa de la época, aborda la hipótesis del ingenio como disposición individual para el ejercicio de determinadas actividades. Véase el trabajo de Martín-Araguz, Antonio y Bustamante-Martínez, Cristina, 2004. 
de este autor con el Tribunal del Santo Oficio y la inclusión de su obra en el Índice de Libros Prohibidos ${ }^{3}$. También son numerosos los autores que aprecian en los planteamientos literarios de Cervantes la influencia de Erasmo de Rotterdam, a través de su famosa obra Elogio de la locura (Moriae encomium, 1509), publicada a principios del siglo XVI, y donde el autor defiende la existencia de una locura positiva, benéfica y divina (Vilanova, 1949; Bataillon, 1966; Castro, 2002). Estas ideas erasmistas, veladamente puestas sobre el tapete por razones evidentes de carácter religioso, máxime en una persona como Cervantes, cuya sangre de cristiano viejo podía ser cuestionada, podrían proceder, además de por su conocimiento directo en sus viajes fuera de España, de su amistad con el médico Antonio Ponce de Santa Cruz (1561-1632), conocedor de las tesis de Erasmo (Rojo Vega, 1983).

No obstante, a pesar de estas supuestas influencias, el único libro de materia médica citado por Cervantes en alguna de sus obras es el Dioscórides comentado por el Doctor Laguna. En este sentido, nosotros planteamos la teoría de que este tratado fuese la fuente utilizada por Cervantes en sus pasajes literarios relativos a aspectos terapéuticos, sobre todo en relación con las plantas dotadas de virtudes medicinales. Esta hipótesis se justifica en el empleo, por parte del autor alcalaíno, de descripciones similares a las aportadas en esta obra científica e incluso, en algún caso, también de citas casi literales de los comentarios de Laguna.

\section{La TeRAPÉutica del Siglo XVI y el DiosCóRIDES DE ANDRÉS LAGUNA}

En el ámbito de la medicina, las teorías imperantes durante el Renacimiento continuaron siendo aquellas basadas en las alteraciones de los humores propuestas por Galeno, aunque con algunas novedades procedentes de las incipientes corrientes iatroquímicas (Puerto, 1997; Montiel, 1998), como las defendidas por Paracelso (Theophrastus Phillippus Aureolus Bombastus von Hohenheim) (1493-1541), quien inspiró nuevas formas de entender la enferme$\mathrm{dad}^{4}$. También, desde la perspectiva terapéutica, el galenismo marcó la manera de abordar el tratamiento de las enfermedades durante esta época. Así, se recurría, básicamente, al empleo de sangrías, sanguijuelas y productos eva-

3. El Examen de ingenios para las ciencias fue publicado inicialmente en Baeza en 1575, pero estuvo incluido, en España, en el Índice de Libros Prohibidos (Index Librorum Prohibitorum et Expurgatorum) de la Sagrada Congregación de la Inquisición hasta 1583, siendo reeditado, con correcciones, en 1594.

4. De orientación alquímica, para Paracelso las enfermedades serían alteraciones del archeus, una especie de organizador de los procesos químicos del organismo, "el alquimista del cuerpo", que controlaría el equilibrio entre los tres principios naturales, o "triada de principios"; mercurius, sulphur y sal. Véase, para profundizar más en este campo, el capítulo de MonTiEL, Luís, 1998. 
cuantes, purgantes o eméticos (Sauri, 1969; Postel y Quétel, 1987) para desviar o eliminar la bilis sobrante y los humores ácidos. Las propiedades terapéuticas de estas últimas sustancias, como, por ejemplo el eléboro (obtenido de la planta Helleborus niger) eran entendidas, en el contexto histórico que nos ocupa, como herramientas de catarsis o purificación, e iban dirigidas a contrarrestar la producción de materia infirmitatis, permitiendo la recuperación de la eukrasía, es decir, la correcta mezcla de humores en que se fundamenta la salud (Montiel, 1998). Los remedios farmacológicos eran, pues, muy escasos, de carácter eminentemente inespecífico y de procedencia fundamentalmente vegetal.

No obstante, es preciso mencionar algunos importantes avances habidos en el campo de la farmacoterapia en la época precervantina. Tal vez, el más importante sea la transformación de los procedimientos alquímicos medievales en disciplina con proyección científica ${ }^{5}$, de forma que la tecnología introducida por los alquimistas se puso, por primera vez durante esta época, al servicio de la farmacología (extracción alcohólica, destilación, calcinación, etc.), con objeto de encontrar nuevos medicamentos. El segundo y trascendente avance fue la incorporación al arsenal farmacoterapéutico disponible en este momento histórico de nuevos fármacos y remedios procedentes de las especies botánicas traídas del Nuevo Mundo, como los extractos de corteza de quina cinchona, usada como tónico en enfermos catalogados como "asténicos", o el tabaco, utilizado como estimulante y "descongestionante cerebral" (López-Muñoz et al., 2005). Del mismo modo, la potenciación del comercio con los países orientales fomentó el conocimiento de nuevos remedios y el resurgir de otros, como el propio opio (Papaver somniferum). No obstante, tanto el opio como otros remedios sedantes (generalmente de procedencia vegetal), a pesar de su amplio empleo clínico, apenas son mencionados en las obras cervantinas, posiblemente por su controvertido y desprestigiado uso extraterapéutico, muy criticado por las autoridades eclesiásticas.

Desde la vertiente académica, la aportación de los médicos humanistas supuso un considerable enriquecimiento del legado clásico (analizado de primera mano, y no deformado por los traductores árabes o por los representantes de las escuelas escolásticas medievales, que lo contaminaron de prejuicios y limitaciones), algo evidente también en el ámbito de la farmacoterapia (Montiel, 1998). De esta forma, durante el Humanismo aparecen las primeras farmacopeas oficiales, con la intención de homogeneizar la composición y las formas de elaboración de las fórmulas prescritas por los médicos de la época ${ }^{6}$. Del mismo modo, los clásicos textos de terapéutica, fundamentalmente el

5. Durante el Humanismo, el concepto de piedra filosofal pierde vigencia y la alquimia sirvió de base para el desarrollo de la química y, por ende, de la farmacología.

6. La primera farmacopea europea se publicó en 1498, en Florencia (Nuovo Receptario Compositio), y la segunda (la célebre Concordie apothecariorum Barchinone medicines Compositis) en Barcelona, en 1511. 
Dioscórides $^{7}$, fueron notoriamente enriquecidos, como se puede apreciar en las famosas ediciones de esta obra realizadas por Pietro Mattioli o por el mencionado Andrés Laguna (Fig. 1) (Dubler, 1953-1959).

El Dioscórides de Laguna fue publicado inicialmente en Lyon, en 1554, con el título Annotaciones in Dioscoridem Anazarbeum, aunque su reimpresión en Amberes, en 1555 (Pedacio Dioscorides Anazarbeo, acerca de la materia medicinal, y de los venenos mortíferos), constituye la versión primigenia fundamental de esta obra, primera realizada en lengua castellana. Prueba de la gran aportación original de Laguna a este compendio clásico es que sus comentarios duplican en extensión el texto completo de Dioscórides, comentarios en los que se incorporan observaciones y opiniones fruto de su amplia experiencia como botánico y especialista en materia terapéutica, y de sus continuos viajes por Europa, donde siempre se ocupó de recoger y estudiar cuantas hierbas y plantas pudo. Del mismo modo, incorporó un sexto libro a este tratado, en el que se describen los diferentes agentes tóxicos y venenosos, junto a sus antídotos y a la forma de tratar los envenenamientos (González Manjarrés, 2000; Sánchez Granjel, 2001). Además, Laguna también incluyó anotaciones sobre plantas procedentes del Nuevo Mundo, como las propiedades antisifilíticas del guayaco, aunque en este caso sus comentarios no fueron de primera mano.

A modo de resumen, podemos afirmar que la práctica de la terapéutica del siglo XVI se puede englobar en dos grandes apartados; la medicina y far-

7. El Dioscórides es la denominación popular y vulgarizada del tratado Sobre la Materia Médica, principal obra científica del médico griego Pedacio Dioscórides Anazarbeo (Anazarba, c. 40 - c. 90), quien trabajó gran parte de su vida como cirujano militar al servicio del ejército romano de Nerón, Calígula y Claudio. El Dioscórides constituye una compilación no solo de los saberes terapéuticos previos, sino de todas las observaciones, fundamentalmente de naturaleza herbal, que Dioscórides fue reuniendo durante sus continuos viajes acompañando el ejército de Roma. En total, el texto describe las propiedades medicinales de unas 600 plantas, unos 90 minerales y alrededor de 30 sustancias de origen animal. La enorme importancia de esta obra se puede extrapolar de su gran pervivencia histórica, que alcanzó hasta el siglo XVIII, siendo el más importante de los tratados sobre medicamentos durante la Edad Media y el Renacimiento, gracias al elevado número de copias, traducciones y ediciones comentadas que se publicaron durante este periodo de 18 siglos. Los ejemplares más antiguos que se conservan de esta obra son el Codex Vindobonensis, versión bizantina elaborada a principios del siglo VI y depositado en la Biblioteca Nacional de Viena, y el Dioscorides Neapolitano, cien años más moderno y conservado en la Biblioteca Nacional de Nápoles. Posteriormente, durante la Edad Media, fue traducido al árabe, tanto en las escuelas de traductores de Bagdad como en las de Córdoba. Durante el Humanismo despertó el interés por las obras clásicas y desde el siglo XV se sucedieron las traducciones latinas, comentadas o no, de la Materia Médica de Dioscórides (Riddle, 1985), destacando la traducción latina de Pietro d'Abano (1250-1315), de 1478, y las posteriores de Ermolao Barbaro (1454-1493) y del canónigo de París, Jean de la Ruelle (1474-1537), ambas de 1516. Sin embargo, la más relevante versión comentada del Dioscórides fue la del médico de Siena, Pietro Mattioli (1500-1577), inicialmente publicada en italiano en 1544 y posteriormente en latín, muy ampliada, en 1554 (Commentarii in libros sex Pedacii Dioscoridis de medica materia). Esta obra, continuamente ampliada, tanto en comentarios como en ilustraciones, continuó imprimiéndose hasta el siglo XVIII, alcanzando las 17 ediciones. La primera edición castellana fue la de Andrés Laguna, en 1555, texto que tuvo un éxito similar al de Mattioli, ya que, hasta el siglo XVIII, fue reimpreso en 22 ocasiones. 
macia popular, es decir, la basada en el empleo de las plantas de herbolarios, accesibles a toda la población, por su carácter económico, y la terapéutica precedente compilada (aunque ampliada) en el Dioscórides, que se aplicaba de acuerdo a la teoría de los cuatro humores purgantes. A estos dos planteamientos habría que sumar el recurso al empleo de metales y minerales (por ejemplo, el mercurio, empleado en el tratamiento de la sífilis o morbo gálico, o el antimonio, usado como emético), defendido por los seguidores de Paracelso (Norton, 2003; Esteva de Sagrera, 2005), y la incorporación de una serie de medicamentos procedentes de América, entre los que destacaba el "palo de guayaco" o Palo Santo (Guajacum officinale), sudorífico empleado contra la sífilis o mal de bubas (Esteva de Sagrera, 2005), además del tabaco (Nicotiana tabacum) y la quina.

\section{El Dioscórides de Laguna EN LA OBRA DE CERVANTES}

Desde el punto de vista terapéutico, varios autores afirman que las obras de Cervantes reflejan fehacientemente los procedimientos terapéuticos de su época y pueden servir como herramienta de estudio para profundizar en el conocimiento de esta disciplina médica en el periodo cervantino (Fraile et al., 2003; Iranzo et al., 2004). Según defiende Esteva de Sagrera (2005), Cervantes parece conocer las virtudes de numerosas plantas disponibles en los herbolarios de su época para el abordaje, popular y económico, de diferentes patologías. De esta misma opinión es Reverte Coma (1992), quien afirma que pudo conocer, entre otras, las propiedades cicatrizantes del romero (Rosmarinus officinalis), las estomacales y vulnerarias del corazoncillo (Hypericum perforatum), las emolientes de la hierba cana (Senecio vulgaris), las astringentes de la hierba de la doncella (Vinca minor), las vermífugas, estomacales y antihelmínticas de la hierba lombriguera (Tanacetum vulgare), las calmantes de la hierba mora o tomatillos del diablo (Solanum nigrum), o las venenosas del eléboro (Helleborus niger). Pero además de las propias plantas medicinales, Cervantes muestra reiteradamente sus conocimientos sobre diferentes preparados de botica elaborados con ellas. Muchos de estos preparados (aceites, ungüentos, bálsamos, raíces, cortezas y jarabes), tan habituales en la farmacopea de la época cervantina (Esteva de Sagrera, 2005), algunos de carácter ficticio y otros de uso real, quedan reflejados en las obras del literato alcalaíno. A título de ejemplo, baste mencionar el famoso bálsamo de Fierabrás, tan reiterado en el Quijote, los polvos de ruibarbo (raíz de Rheum officinale -ruibarbo chino- o Rumex alpinus -ruibarbo de los monjes-), uno de los agentes terapéuticos purgantes más empleados en la época humanística, el ungüento blanco o el aceite de Aparicio.

Posiblemente, el amplio conocimiento de las plantas, algunas con propiedades curativas, y de los preparados de botica que exhibe Cervantes proceda de la lectura y de la consulta de obras técnicas, como la famosa edición del Dioscórides editada por Andrés Laguna y considerada como un manual de re- 
ferencia en esta materia durante siglos. Un comentario vertido en el Quijote da pie a pensar que esto fuese así:

"Con todo respondió Don Quijote, tomara yo ahora más aina un quartal de pan o una hogaza y dos cabezas de sardinas arenques, que cuantas yerbas describe Dioscórides, aunque fuera el ilustrado por el Doctor Laguna" (I, XVIII, p. 195) ${ }^{8}$.

La relevancia de los conocimientos botánicos contenidos en esta obra también difunde en otros pasajes del Quijote y de otras novelas cervantinas. Así, Don Quijote afirma que "el caballero andante... ha de ser médico, y principalmente herbolario, para conocer... las yerbas que tienen la virtud de sanar las heridas" (II, XVIII, p. 368).

Cervantes, quien contaba 13 años cuando falleció el ilustre médico segoviano, fue un hombre inquieto que vivió en una época de grandes incertidumbres, un periodo histórico de transición en el que las humanistas formas de entender el mundo fueron dejando paso, desde la perspectiva cultural, a un enrevesado barroquismo, y desde la vertiente política, al menos en España, a un incipiente periodo de decadencia imperial. En este sentido, las vidas de Laguna ${ }^{9}$ y Cervantes comparten muchos paralelismos y afinidades. Ambos proceden de familia de médicos, residen en algún momento de su vida en una pequeña ciudad universitaria como es Alcalá de Henares, y comparten el hecho de ser cristianos nuevos ${ }^{10}$. Este último factor suponía, en el momento que les tocó vivir, un lastre de gran importancia, máxime a la hora de expresar y difundir sus talentos culturales o científicos. Del mismo modo, diversos autores han visto en

8. En el presente trabajo, hemos empleado la edición de las Obras Completas de Cervantes de Florencio Sevilla, Madrid, Editorial Castalia, 1999.

9. Andrés Fernández de Laguna (Segovia, 1499 - Guadalajara, 1560), hijo de médico judeoconverso, fue una de las más brillantes figuras de la cultura humanista europea del siglo XVI. Después de cursar estudios en diferentes universidades españolas, Laguna estudió artes, lenguas clásicas y medicina en París, entre 1530 y 1536, siendo discípulo directo de Jean de la Ruelle, uno de los primeros traductores de Dioscórides. Tras su regreso a España, en 1536, ejerció de profesor en la Universidad de Alcalá de Henares, aunque pronto inició sus habituales periplos viajeros, primero por Inglaterra y posteriormente, acompañando al Emperador Carlos V, del que fue médico personal, por los Países Bajos y Alemania, instalándose finalmente como médico en la ciudad de Metz, en Lorena, entre 1540 y 1545. Su inquieta vida continuó en Italia, donde permaneció hasta 1554, siendo nombrado doctor por la Universidad de Bolonia y alcanzando el puesto de médico personal del papa Julio III. Tras sendas estancias en Venecia, junto al embajador español y gran humanista Diego Hurtado de Mendoza (15031575), y en los Países Bajos, regreso a España en 1557, siendo también médico del rey Felipe II. Aunque escribió más de 30 obras de diversas materias, incluyendo las de orden filosófico, histórico, político y literario, además de las estrictamente médicas, la obra más conocida de Laguna es la traducción comentada de la Materia Médica de Dioscórides. Para profundizar en la biografía de Andrés Laguna pueden consultarse los trabajos de Hernando, Teófilo, 1990; Sánchez Granjel, Luís, 2001; Pardo TomÁs, José, 2002; Font Quer, Pío, 2003.

10. No cabe duda de que Laguna fue un converso de primera generación. Sin embargo, en el caso de Cervantes su ascendencia judía es motivo de controversia (véase CANAVAGGIO, Jean, 2004), siendo varios los autores que afirman que es evidente esta procedencia por ambas ramas familiares, aunque más recientemente por la parte materna (Munguía, Víctor Eduardo, 1995). 
las obras de ambos autores claras e importantes influencias erasmistas, más evidentes en el caso de Laguna, defensor de las ideas de tolerancia y paz universal y a quien el propio Erasmo rindió tributo en 1548 por sus estudios humanísticos, pero también en Cervantes, como se ha comentado. Otra coincidencia vital entre Laguna, quién también cultivó la literatura, y Cervantes es su naturaleza errante, hecho que marcaría de forma evidente sus trayectorias personales y sus producciones escritas ${ }^{11}$.

Según apunta Eisenberg (2002), Cervantes era muy aficionado a mencionar, comentar e incluso criticar en sus obras literarias muchos de los libros y manuscritos de los que disponía en su biblioteca particular, lo que refuerza la hipótesis de que el Dioscórides, un ejemplar del cual era propiedad del literato alcalaíno, como hemos comentado, constituyese la fuente de referencia cervantina en materia terapéutica. Además, según postula Baranda (1993), Laguna redactó sus comentarios al Dioscórides mediante un discurso universal, de forma que pudiesen ser utilizados y entendidos, además de por los profesionales de la medicina de la época, por personas legas en materia terapéutica ${ }^{12}$. Para ello, Laguna recurre habitualmente a anécdotas, relatos de experiencias propias, leyendas de países lejanos, etc., con el objetivo de hacer la lectura más asequible y amena a los no especialistas. Bajo estos parámetros, su consulta por parte de personas como Cervantes resultaría más asequible, lo que incide aún más en nuestra hipótesis de que el literato lo utilizase como fuente documental de carácter técnico.

En su reconstrucción de la biblioteca de Cervantes, la edición del Dioscórides reseñada por Eisenberg (2002) fue Pedacio Dioscórides Anazarbeo, acerca de la materia medicinal, y de los venenos mortíferos, Traduzido de la lengua Griega, en la vulgar Castellana, \& illustrado con claras y substanciales annotaciones, y con las figuras de innumeras plantas exquisitas y raras, por el Doctor Andrés de Laguna, Médico de Iulio III. Pont. Maxi. Libro editado en Salamanca. Si este libro corresponde, como indica el investigador, al legado paterno, debía corresponder a la edición salmantina de 1563, o una de sus reimpresiones de 1566 o 1570, ya que en 1585 falleció Rodrigo de Cervantes ${ }^{13}$.

Teniendo en consideración todos los puntos previamente comentados, nosotros postulamos la hipótesis del conocimiento técnico por parte de Cervantes de la materia médica de Laguna, al constatar como el autor del Quijote transcribe en sus obras planteamientos muy similares a los comentarios del médico

11. No deja de ser casual, en este sentido, que el principal personaje de la obra anónima Viaje de Turquía (1557), una de las más prestigiosas creaciones literarias humanísticas de carácter erasmista y atribuida por algunos investigadores, como célebre hispanista francés Marcel Bataillon (1895-1977), al propio Laguna (BATAILlon, Marcel, 1958), sea un médico llamado Pedro de Urdemalas, nombre que, pese a su carácter popular en el marco de la narrativa del siglo XVI, es utilizado también por Cervantes para designar al personaje central y al título de una comedia de este autor, publicada 58 años después.

12. Como resalta Baranda, Consolación "Los lectores del Dioscórides...", p. 24, "la duplicidad de estrategias discursivas de Laguna pone en evidencia su esfuerzo por ampliar el ámbito de la recepción de su libro; con ello pretendió popularizar la medicina académica y en este aspecto tuvo un éxito innegable".

13. Nosotros hemos utilizado la edición salmantina del Dioscórides de Laguna de 1563, la misma que pudo manejar Cervantes, impresa, con privilegio, en la casa de Mathias Gast. 
segoviano en su Dioscórides, llegando, en algún caso, a citar casi literalmente ciertos párrafos de ellos (Tabla I). Sin embargo, es preciso tener siempre en mente que el objetivo de Cervantes al escribir sus obras no era el de disertar sobre aspectos terapéuticos, sino el del mero entretenimiento propio de una construcción literaria, donde las pinceladas técnicas constituyen un adorno más y un recurso para demostrar cierto carácter ilustrado. Bajo este último prisma se posicionan algunos autores, como Puerto (2005b), que defienden que Cervantes, a pesar de citar el Dioscórides de Laguna, nunca lo leyó.

Tabla I: Comparación y concordancia entre diferentes pasajes de los textos literarios de Cervantes y párrafos extraídos de las anotaciones previas de Laguna a su Dioscórides.

\begin{tabular}{|c|c|c|c|c|}
\hline $\begin{array}{l}\text { Planta o } \\
\text { preparado }\end{array}$ & Cita de Cervantes & Obra & Cita de Laguna & $\begin{array}{l}\text { Capítulo del } \\
\text { Dioscórides }\end{array}$ \\
\hline Ruibarbo & $\begin{array}{l}\text { "tiene necesidad de un poco de } \\
\text { ruibarbo para purgar la demasiada } \\
\text { cólera suya" }\end{array}$ & $\begin{array}{l}\text { El Quijote (Parte I, } \\
\text { capítulo VI) }\end{array}$ & $\begin{array}{l}\text { "por donde cuando decimos que el } \\
\text { reobárbaro purga la cólera", }\end{array}$ & II (Libro III) \\
\hline Romero & $\begin{array}{l}\text { "Y tomando algunas hojas de } \\
\text { romero..., las mascó y las mezcló } \\
\text { con un poco de sal, y aplicándoselas } \\
\text { a la oreja, se la vendó muy bien, } \\
\text { asegurándole que no había menester } \\
\text { otra medicina" }\end{array}$ & $\begin{array}{l}\text { El Quijote (Parte I, } \\
\text { capítulo XI) }\end{array}$ & $\begin{array}{l}\text { "majadas las hojas [de romero] y } \\
\text { aplicadas en forma de emplasto... } \\
\text { mitigan las inflamaciones" }\end{array}$ & $\begin{array}{l}\text { LXXXIII (Libro } \\
\text { III) }\end{array}$ \\
\hline $\begin{array}{l}\text { Ungüentos } \\
\text { de brujas }{ }^{1}\end{array}$ & $\begin{array}{l}\text { "jugos de yerbas en todo extremo } \\
\text { fríos" } \\
\text { "nos privan de todos los sentidos" } \\
\text { "en la fantasía pasamos todo aquello } \\
\text { que nos parece pasar verdaderamente" } \\
\text { "gozamos de los deleites que te dejo } \\
\text { de decir" } \\
\text { "llegaron a hincarle alfileres... ni } \\
\text { por eso recordaba la dormilona" }\end{array}$ & $\begin{array}{l}\text { El coloquio de } \\
\text { los perros }\end{array}$ & $\begin{array}{l}\text { "compuesto de yerbas en último grado } \\
\text { frías" } \\
\text { "priva del entendimiento y sentido" } \\
\text { "creen haber hecho despiertas todo } \\
\text { cuanto soñaron durmiendo" } \\
\text { "estaba rodeada de todos los placeres } \\
\text { y deleites del mundo" } \\
\text { "fue difícil despertarla, aun utilizando } \\
\text { diversos medios" }\end{array}$ & $\begin{array}{l}\text { LXXV (Libro } \\
\text { IV) }\end{array}$ \\
\hline $\begin{array}{l}\text { Unturas } \\
\text { alopiadas }^{2}\end{array}$ & $\begin{array}{l}\text { "tenía tal virtud que, fuera de quitar } \\
\text { la vida, ponía a un hombre como } \\
\text { muerto" }\end{array}$ & $\begin{array}{l}\text { El celoso } \\
\text { extremeño }\end{array}$ & $\begin{array}{l}\text { "le hará dormir in aeternum... } \\
\text { adormece de un tan profundo sueño } \\
\text { que no despierta jamás" }\end{array}$ & $\begin{array}{l}\text { LXVI (Libro IV) } \\
\text { XVII (Libro VI) }\end{array}$ \\
\hline Tósigos ${ }^{3}$ & $\begin{array}{l}\text { "se le comenzó a hinchar la lengua } \\
\text { y la garganta, y a ponérsele } \\
\text { denegridos los labios, y a } \\
\text { enronquecérsele la voz, turbársele } \\
\text { los ojos y apretársele el pecho" }\end{array}$ & $\begin{array}{l}\text { La española } \\
\text { inglesa }\end{array}$ & $\begin{array}{l}\text { "apostémaseles la lengua, hínchaseles } \\
\text { la boca, inflámaseles y paréceles } \\
\text { turbios los ojos, estréchaseles el } \\
\text { aliento... y una comezón de las encías, } \\
\text { y en todo el cuerpo" }\end{array}$ & XV (Libro VI) \\
\hline
\end{tabular}

${ }^{1}$ Solanáceas (solano / beleño), ${ }^{2}$ Papaveráceas (opio), ${ }^{3}$ Solanáceas (beleño o Hyoscyamo)

\section{Las plantas medicinales en las obras de Cervantes}

En un minucioso estudio botánico sobre las plantas mencionadas en las obras completas de Cervantes, Morales (2005) obtuvo 835 referencias, correspondientes a 150 especies distintas, de las que sólo 9 fueron clasificadas por el autor como de carácter medicinal. Sin embargo, nosotros hemos encontrado 10 plantas mencionadas en los textos cervantinos por sus hipotéticas propiedades terapéuticas, psicotrópicas o nocivas para la salud: la achicoria (Cichorium intybus), la adelfa (Nerium oleander), el beleño (Hyosciamus albus / niger), el opio, el romero, el ruibarbo, el tabaco, el tamarisco (Tamarix gallica), el tártago (Euphorbia lathyris) y la verbena (Verbena officinalis). 


\section{A propósito de los purgantes y la alteración de los humores en el Quijote}

Los purgantes son mencionados en el Quijote precisamente en el sentido que durante el momento de su elaboración se daba a estos agentes en el marco de la salud general, esto es, como sustancias capaces de lograr la eliminación de los humores morbosos, permitiendo una purificación espiritual. Entre estos agentes se encontraba el ruibarbo ("reobárbaro", en el léxico de Laguna). El rizoma de ruibarbo de los monjes (Rumex alpinus), planta que crece en el Norte de España, posee propiedades purgantes y tónicas, gracias a su riqueza en ácidos tánico y crisofánico, y era empleado para purgar los humores colérico y flemático ${ }^{14}$ (Valle, 2002). Además, en la Península Ibérica crecen abundantemente los lapatos o acederas (Rumex acetosa), una planta vulgarmente llamada 'romaza', y cuyo rizoma también es rico en ácido crisofánico. En relación con la raíz de esta planta, Laguna comenta que "por conocerse en ella una valerosa virtud laxativa, la administramos ordinariamente los médicos, en lugar del ruibarbo, para purgar la cólera, por lo que muchos varones doctos la tienen por verdadero ruibarbo" (p. 200). Cervantes, en el Quijote, hace referencia al uso de ruibarbo, cuando el señor cura del lugar del que Cervantes no quería acordarse comenta, en relación al hidalgo: "tiene necesidad de un poco de ruibarbo para purgar la demasiada cólera suya" (I, VI, p. 164). Esta sentencia parece extraída literalmente de las conclusiones del médico segoviano sobre las virtudes de esta raíz ("por donde cuando decimos que el reobárbaro purga la cólera", p. 264) (Tabla I), hecho que parece respaldar la hipótesis de la lectura del Dioscórides por parte de Cervantes.

\section{Las plantas dotadas de propiedades hipnóticas y narcóticas en los textos cervantinos}

Entre las plantas dotadas de propiedades narcóticas, fundamentalmente de la familia de las solanáceas, Cervantes únicamente cita en sus obras al beleño, que es mencionado en La Galatea recordando sus propiedades hipnóticas ("Tu has quitado la fuerza al beleño, / con que el amor ingrato / adormecía a mi virtud doliente", V, p. 111), aunque también brevemente en Viaje del Parnaso ("Morfeo, el dios del sueño, por encanto / allí se apareció, cuya corona / era de ramos de beleño santo", VIII, p. 1215). El beleño, conocido a nivel popular como "hierba loca" y "flor de la muerte", es una planta, al igual que el resto de las solanáceas (belladona -Atropa belladonna-, mandrágora - Mandragora officinarum-, estra-

14. Esta especie de ruibarbo era cultivada habitualmente en los claustros de los monasterios con destino a la botica monacal. Además, hay que hacer constar la existencia de otro tipo de ruibarbo (Rheum spp.), conocido popularmente como 'ruibarbo chino' y dotado también de las mismas propiedades laxantes (véase Foust, Clifford M., 1992). Sin embargo, su exótico origen (Oriente lejano) prácticamente imposibilitó su uso popular en la España del siglo XVI. 
monio - Datura stramonium-, etc.), muy rica en alcaloides dotados de una gran actividad sedante, como la hiosciamina y la escopolamina, y se venía utilizando desde la Edad Media como agente narcótico en la práctica de la medicina oficial (Cabanés, 2006). De las flores de esta planta, denominada hyoscyamo por Laguna, dice el Dioscórides que "engendran sueños muy graves" (p. 417).

Por otro lado, Cervantes menciona el agua de achicoria en el famoso pasaje de la aventura de los molinos en el Quijote: "Toda aquella noche no durmió Don Quijote, pensando en su señora Dulcinea... No la pasó así Sancho Panza, que, como tenía el estómago lleno, y no de agua de chicoria, de un sueño se la llevó toda" (I, VIII, pp. 167-168). Este remedio se obtenía destilando en agua sumidades de Cichorium intybus, y era muy utilizado en el tratamiento del insomnio, además de templar el encendimiento del hígado y abrir las opilaciones. En líneas generales, se trataba de un agente tónico y estomacal (Font Quer, 2003). Andrés Laguna describe detalladamente una variante salvaje de este tipo de endivia, denominada hedypnois, destacando que se trata de una sustancia "acarreadora de dulce sueño, porque hace dormir sin cuidado" (p. 215). Esta aproximación de Cervantes a las propiedades farmacológicas de esta planta apuntala aún más la hipótesis de que su conocimiento de la obra del ilustre médico segoviano no era superficial.

\section{Bálsamos, emplastos, ungüentos y bizmas: la farmacoterapia trau- matológica en el Quijote y el poder del romero}

Tras una detallada lectura médica de los textos cervantinos, se puede afirmar que su autor, más que contemplar el uso de agentes de acción farmacológica primaria, suele recurrir con más frecuencia al uso de diferentes preparados de botica con efectos farmacológicos secundarios o diferidos, como ciertos bálsamos, ungüentos, emplastos y aceites reparadores, sobre todo en relación con el abordaje terapéutico de las heridas y traumatismos. Uno de ellos es el denominado 'ungüento blanco'15, remedio propuesto en el Quijote por Sancho para, con la ayuda de 'hilas' ${ }^{16}$, controlar el sangrado de una herida en la oreja de su señor "que le dolía más de lo que es menester" (I, XI, p. 175). El hecho de que el escudero contase con este preparado en sus alforjas, habla de su popularidad durante el siglo XVI. Según el Antidotario de los medicamentos

15. Aunque en la época cervantina existían, con este mismo nombre, varios preparados con diferentes ingredientes, posiblemente al que se refiere Cervantes en el Quijote sea el recogido en el Antidotario de los medicamentos compuestos de Juan Fragoso (1530-1597), y que estaba compuesto de albayalde, aceite rosado y cera de abejas. Una modificación de este ungüento aparece en la Pharmacopea Matritensis (1739) con el nombre de "ungüento blanco sarraceno", entre cuyos ingredientes también se incluyen litargirio, claras de huevo, pasta de semillas de calabaza, polvo de almáciga, alcanfor disuelto en alcohol, vinagre rosado y, finalmente, sebo en vez de cera. Otro ungüento de este tipo, como el integrado por manteca y carbonato de plomo porfirizado, denominado "unguentum album ex Rhassis", está recogido en la Pharmacopea Hispana (1794).

16. Hebras obtenidas de trapos de lienzo usadas para cubrir heridas y llagas, a modo de gasas. 
compuestos de Juan Fragoso (1530-1597), este ungüento se hacía con cera, albayalde y aceite rosado, y precisamente, en relación con el albayalde, al que en el Dioscórides se denomina cerusa, Laguna anota que "mezclado con aceite violado y dos yemas de huevos, es una singular medicina contra el dolor..." (p. 537). No obstante, Don Quijote fue finalmente curado de la herida en la oreja por un cabrero, quien hizo un emplasto con romero y sal: "Y tomando algunas hojas de romero, del mucho que por allí había, las mascó y las mezcló con un poco de sal, y aplicándoselas a la oreja, se la vendó muy bien, asegurándole que no había menester otra medicina, y así fue la verdad" (I, XI, p. 175). No deja de ser curioso, en este sentido, que en el Dioscórides se especifique, en relación con el romero, que "majadas las hojas y aplicadas en forma de emplasto... mitigan las inflamaciones, ... y maduran los lamparones y cualesquiera otros apostemas rebeldes... Aplicadas en forma de emplasto, resuelven las hinchazones" (pp. 320-321) (Tabla I).

En numerosos pasajes del Quijote, sobre todo tras alguna de las abundantes heridas o golpes sufridos por los protagonistas, el autor hace referencia al acto de "bizmar". Las "bizmas" eran emplastos compuestos de estopa, aguardiente, incienso, mirra y otros ingredientes que tenían por finalidad aliviar el dolor y la inflamación de los golpes y traumatismos. Uno de estos emplastos, denominado 'aceite de Aparicio'17 fue aplicado a Don Quijote por la enamorada Altisidora para curarle ciertas heridas, a pesar de su elevado precio (que fundamentó en este remedio el dicho popular "caro como aceite de Aparicio"). Entre los ingredientes de este preparado, además del romero, se encuentra el hipérico, "corazoncillo" o hierba de San Juan (Hypericum perforatum). En la época de Cervantes ya se conocían las propiedades cicatrizantes del hipérico ${ }^{18}$, aunque el autor no cita expresamente esta planta en sus obras. Sin embargo, Laguna si comenta, a propósito del corazoncillo, que "prepárase con las flores del legítimo hypérico un aceite admirable para soldar las heridas frescas... y guardarlas de corrupción" (p. 373).

Finalmente haremos mención del salutífero y eficaz bálsamo de Fierabrás ${ }^{19}$, especie de panacea para cualquier problema de salud, según Don Quijote, y que

17. El aceite de Aparicio, denominado también técnicamente Oleum Magistrale, y cuya composición fue un gran secreto hasta el siglo XVIII, en que se publicó su composición en la Pharmacopea Hispana (Madrid, 1794), debe su nombre a Aparicio de Zubia (?-1566), un curandero morisco natural de Lequeitio que inventó dicha fórmula (véase UNGERER, Gustav, 1986), compuesta, además de por romero e hipérico, por aceite de oliva, mirra, trementina, lombrices y resina de enebro, entre otros ingredientes.

18. El hipérico era conocido también como "hierba militar", al ser utilizado por los caballeros de San Juan de Jerusalén para el tratamiento de las heridas ocurridas en los campos de batalla durante las Cruzadas.

19. Según la tradición compilada en la Historia Caballeresca de Carlomagno, Fier-a-bras ("el de brazo feroz") era un gigante sarraceno, hijo del emir Balante (señor de las Españas), que portaba en su caballo dos barriles con bálsamo sustraídos en Jerusalén, y procedentes del que había sido empleado en la sepultura de Jesús. En el transcurso de un combate, el gigante perdió los barriles, que fueron encontrados por su enemigo Oliveros, uno de los Doce Pares de Francia, quien bebió del bálsamo y curó de sus heridas mortales. Hay que tener presente, en este sentido, que una versión de este cantar adquirió una cierta popularidad en la España del siglo XVI, al publicarse en Sevilla una traducción al castellano del mismo. 
constituye el único preparado medicinal que surge de la fantasía del autor en los textos cervantinos. Este remedio estaría compuesto, según se relata en el Quijote, por aceite, vino, sal y romero, siguiendo un proceder habitual en la práctica de la farmacia de la época, a saber, la mezcla de varios simples medicinales (tres de procedencia vegetal y uno mineral) para obtener un compuesto, al estilo de las famosas triacas (López, 1996; Puerto, 2005a). La elaboración del bálsamo también es descrita por Don Quijote; los cuatro componentes ("simples") deben ponerse al fuego en una olla y cocer durante largo rato, para finalmente el producto ("compuesto") ser vertido en una alcuza de hojalata, sobre la que decir, a modo de ensalmo, "más de ochenta paternoster y otras tantas avemarías, salves y credos, acompañando a cada palabra una cruz a modo de bendición" (I, XVII, p. 190), imprescindible para que el bálsamo sea eficaz. Del mismo modo, son descritos los efectos del bálsamo de Fierabrás: inicialmente un vómito intenso, seguido de gran sudor y fatiga y posteriormente un profundo sueño. Al despertar (tres horas después), el efecto reparador era tan marcado que el hidalgo creyó estar completamente curado. De sus ingredientes, vuelve a destacar el romero. De esta planta, a la que se le han atribuido abundantes propiedades terapéuticas ${ }^{20}$, escribía Laguna en su adaptación del Dioscórides:

"comida su flor en conserva, conforta el celebro, el corazón y el estómago; aviva el entendimiento, restituye la memoria perdida, despierta el sentido, y, en suma, es saludable remedio contra todas las enfermedades frías de cabeza y de estómago... Sirve su sahumerio contra la tos, el catarro y el romadizo" (p. 321).

Por su parte, el aceite, en la práctica de la botica del siglo XVI, se usaba habitualmente para la disolución de principios activos, en la elaboración de ungüentos, linimentos, etc. En concreto, el aceite de oliva se ha empleado, en el marco de los usos tradicionales, en el tratamiento de trastornos digestivos, para facilitar la función urinaria y digestiva, y como colerético, colagogo y laxante (Bruneton, 2001). Si Cervantes leyó a Laguna, no es de extrañar que adoptara estos dos ingredientes, fundamentalmente el romero, tan alabado terapéuticamente por el médico segoviano, como elemento de su fantástico y salutífero bálsamo ${ }^{21}$.

En este sentido, algunos autores, como Prieto (2005) y Morales (2005), plantean la posibilidad de que la receta descrita por Cervantes en relación con la elaboración del bálsamo de Fierabrás estuviese basada en formulaciones reales disponibles en su época. De hecho, se atribuye al médico por-

20. Perteneciente a la familia de las Lamiaceae, el romero ha sido reconocido por sus propiedades coleréticas, diuréticas, espasmolíticas, estimulantes y vulnerarias. Véase BRUNETON, Jean, 2001.

21. Durante el siglo XVI, el romero entró a formar parte de la composición de numerosos preparados, algunos de tipo cosmético, como el Agua de la Reina de Hungría, y otros medicinales, como los bálsamos de Opodeldoc, de Porras, de Aparicio o el bálsamo tranquilo. Véase FonT QueR, Pío, 2003, p. 653 . 
tugués Petrus Hispanus (1215-1277), futuro papa Juan XXI, la redacción, a partir de 1272, de un libro titulado Thesaurus pauperum, en el que se recoge una fórmula muy parecida (cocción de romero en aceite de oliva) con los mismos fines; la obtención de "un ungüento muy precioso y muy virtuoso" 22 . Por su parte, Morales (2005) apunta que Cervantes pudo conocer durante su estancia en Italia una especie de panacea para el tratamiento de múltiples enfermedades, esta vez de uso real y no figurado, denominada bálsamo de Fioravanti, muy de moda durante el siglo XVI y que estaba compuesta por trementina, incienso, mirra, resina, clavo, jengibre, canela, laurel, etc., todo ello previamente macerado en alcohol. Dado que a este bálsamo se le atribuían propiedades milagrosas, sobre todo en el tratamiento tópico de las heridas, bien pudiera ser que sirviera de inspiración a Cervantes para idear su bálsamo de Fierabrás, con diferentes ingredientes, pero con la misma intención.

\section{Otras plantas medicinales y/o tóxicas citadas por Cervantes en sus obras literarias}

Del resto de plantas dotadas de propiedades terapéuticas y mencionadas en los textos cervantinos también se pueden extraer correlaciones con los comentarios de Laguna en su Dioscórides, aunque la consistencia de estas conexiones es bastante más débil, bien porque Cervantes se refiere a ellas de forma soslayada, metafórica o figurada o porque los comentarios vertidos reflejan propiedades vulgarmente conocidas y manejadas por la población general, lega en la materia médica. En su comedia teatral Pedro de Urdemalas, Cervantes menciona la verbena, planta a la que se adjudicaban propiedades mágicas ("hierba sagrada" o "hierba de los hechizos"): "Aquí verás la verbena, / de raras virtudes llena" (p. 1101). Laguna comenta que "llámanla hierba sagrada por ser útil para purgar la casa de adversidades, colgándose de ella" (p. 411), y le da varios y diversos usos, como para el alivio de los dolores de cabeza y del fuego de San Antón, fortalecimiento del cabello, endurecimiento de los miembros inferiores, antídoto contra los venenos, efecto procoagulante, etc. Con respecto a la adelfa, Cervantes se refiere en varias de sus obras a su carácter amargo y ponzoñoso, como en La Galatea ("composición venenosa / con jugo de adelfa amarga", VI, p. 134) o en el Quijote (“... y tan amargo que en su composición son dulces las tueras y sabrosas las adelfas", II, XXXIX, p. 421), pasajes elaborados en el mismo estilo que las anotaciones de Laguna (“... a causa de su notable amargor, solemos rogar a Dios, que a la hembra desamorada, a adelfa le sepa el agua", p. 429). Finalmente, en el entremés El rufián viudo, llamado Trampagos, Cervantes pone en voz de uno de sus personajes las hipotéticas virtudes del tamarisco: “... y que con agua 
de taray pudiera vivir, si la bebiera, setenta años" (p. 1128). Desde una posición más técnica, también Laguna apunta que "tiene el tamarisco virtud de mundificar" (p. 72).

La única planta citada por Cervantes en relación a sus propiedades farmacológicas y que no está recogida en el Dioscórides de Laguna es el tabaco, planta procedente del Nuevo Mundo. Sin embargo, esta planta, como algunas otras especies botánicas americanas, apenas acababan de introducirse en España en el momento en que el médico segoviano escribió su obra ${ }^{23}$. Uno de los primeros usos del tabaco fue como agente capaz de estimular el cerebro y la imaginación, sobre todo en casos de fatiga intelectual (Font Quer, 2003). Precisamente esta última propiedad es a la que se refiere Cervantes cuando menciona esta planta en su obra poética Viaje del Parnaso: "Esto que se recoge es el tabaco / que a los váguidos sirve de cabeza / de algún poeta de celebro flaco; / Urania de tal modo lo adereza, / que, puesto a las narices del doliente, / cobra salud y vuelve a su entereza" (VIII, p. 1215).

Formulaciones de composición no especificada: sobre los poderes mágicos de las plantas

Además de las plantas dotadas de propiedades curativas, Cervantes hace referencia en algunas de sus obras a formulaciones galénicas elaboradas con diferentes hierbas y destinadas, generalmente, a usos extraterapéuticos, en el marco de la tradición mágica imperante aún durante el Humanismo tardío español. Incluso algunos de estos preparados, elaborados por personas no cultivadas, ajenas a la materia médica y perseguidas por los responsables eclesiásticos, constituyen el eje central del discurso narrativo de varias de las $\mathrm{No}$ velas ejemplares cervantinas. Sin embargo, a pesar de que Cervantes no incide en la hipotética composición de estos preparados herbales utilizados a nivel popular, cuando glosa sus efectos y propiedades, nos permite intuir claramente la naturaleza de sus supuestos ingredientes, como posteriormente se discutirá. En este sentido, la ausencia de menciones específicas a estos ingredientes o "compuestos simples" posiblemente no se deba a la ignorancia del autor, que como hemos intentado demostrar no era ajeno a la materia médica y terapéutica, sino, como postulan varios autores (Fraile et al., 2003) y también defendemos nosotros, a un exceso de celo frente a las autoridades del Santo Oficio, que veían con malos ojos este tipo de medicinas. No debemos olvidar, en este punto, la especial vulnerabilidad del literato, que, cuestionado como cristiano viejo, debía dejar inmaculada de forma permanente su limpieza de sangre.

23. Piénsese que la famosa Historia medicinal de las cosas que se traen de nuestras Indias Occidentales que sirven en medicina, de Nicolás Monardes (1493-1588), no fue publicada hasta 1574, 19 años después de la primera edición del Dioscórides. 


\section{Los ungüentos de brujas en El coloquio de los perros}

Laguna pudo ser, en opinión de Rothman (1972), el primer científico que demostró la correlación existente entre el consumo de sustancias psicotrópicas (contenidas en las plantas de la familia de las Solanaceae) y la práctica de la brujería. Estas plantas, como la dulcamara o hierba mora (Solanum spp.), el beleño, la belladona y la mandrágora se venían utilizando desde la Edad Media como elementos integrantes de las pócimas de hechiceros y los ungüentos de brujas, debido a sus efectos alucinógenos (Harner, 1973; Caro Baroja, 1990). En sus anotaciones del Dioscórides, Laguna describe estos efectos y sensaciones placenteras (similares a las ocasionadas por el opio), pero, además, fue capaz de demostrarlos experimentalmente, al aplicar estas unturas de brujas a sujetos normales (la mujer de un verdugo municipal afecta de insomnio), concluyendo que estas drogas ("raíces que engendran locura") ocasionan un incremento de la sugestibilidad, induciendo una especie de trastorno mental transitorio. Estos apuntes de naturaleza psiquiátrica abrieron una nueva luz sobre la visión social de las brujas y hechiceras, que comenzaron a dejar de considerarse como poseídas y ser evaluadas desde la perspectiva de sujetos enajenados.

En el capítulo correspondiente al solano que engendra locura ("la que saca de tino" y "priva del entendimiento y sentido", en palabras de Laguna) o hierba mora, una planta solanácea dotada de importantes efectos alucinógenos (Font Quer, 2003), comenta Laguna en relación a su consumo:

\footnotetext{
"representa ciertas imágenes vanas, pero muy agradables, lo cual se ha de entender entre sueños. Esta pues debe ser (según pienso) la virtud de aquellos ungüentos, con que se suelen untar las brujas: la grandísima frialdad de los cuales, de tal suerte las adormece, que por el diuturno y profundísimo sueño, las imprime en el cerebro tenazmente mil burlas y vanidades, de suerte que después de despiertas confiesan lo que jamás hicieron” (p. 321).
}

A partir de este momento, relata Laguna una historia que le sucedió, en relación a estas pócimas de brujas, siendo médico asalariado de la ciudad de Metz, en Lorena. En la casa de unos brujos condenados por las autoridades se encontró una olla medio llena de un ungüento verde, "con el que se untaban, cuyo olor era tan grave y pesado, que mostraba ser compuesto de yerbas en último grado frías y soporíferas: cuales son la cicuta, el solano, el beleño y la mandrágora" (p. 422). Posteriormente, ensayó Laguna esta pócima con una mujer afecta de tan profundos celos que "había totalmente perdido el sueño y vuéltose casi medio frenética". Tras ser untada, la mujer entró en un profundo sueño, de 36 horas de duración, del que fue difícil despertarla, aun utilizando diversos medios: "fuertes ligaduras y fricciones de las extremidades, con perfusiones de aceite de costino y de euforbio, con sahumerios y humos a narices, y finalmente con ventosas". Al despertar, la mujer comentó que "estaba rodeada de todos los placeres y deleites del mundo..." (p. 422). 
Por su parte, Cervantes hace referencia a estos ungüentos de brujas en su novela ejemplar El coloquio de los perros, cuando Berganza comenta las actividades de una de sus amas, una anciana conocida como la Cañizares, que le confiesa la práctica de actos propios de brujas:

"Este ungüento con que las brujas nos untamos es compuesto de jugos de yerbas en todo extremo fríos... y digo que son tan frías, que nos privan de todos los sentidos en untándonos con ellas, y quedamos tendidas y desnudas en el suelo, y entonces dicen que en la fantasía pasamos todo aquello que nos parece pasar verdaderamente" (p. 678).

Asimismo, Cervantes describe magistralmente en este pasaje los efectos psicotrópicos de las mezclas de agentes alucinógenos administrados por vía tópica (viajes extracorpóreos, alucinaciones visuales, sensaciones placenteras, etc.):

\begin{abstract}
"acabadas de untar, a nuestro parecer, mudamos forma, y convertidas en gallos, lechuzas o cuervos, vamos al lugar donde nuestro dueño nos espera, y allí cobramos nuestra primera forma y gozamos de los deleites que te dejo de decir... buenos ratos me dan mis unturas... y el deleite mucho mayor es imaginado que gozado...; y, sacando de un rincón una olla vidriada, metió en ella la mano, y, murmurando entre dientes, se untó desde los pies a la cabeza... Antes que se acabase de untar me dijo que, ora se quedase su cuerpo en aquel aposento sin sentido, ora desapareciese de él, que no me espantase... Curiosos hubo que se llegaron a hincarle alfileres por las carnes, desde la punta hasta la cabeza: ni por eso recordaba la dormilona" (p. 678).
\end{abstract}

La enorme semejanza entre los textos de Laguna y Cervantes parece confirmar el uso por parte del literato de las anotaciones del científico. Incluso algunos párrafos parecen ser representados de forma casi literal, como mostramos en la Tabla I. Además, llama especialmente la atención la referencia de Cervantes a las propiedades farmacológicas de estos ungüentos, a los que, siguiendo la descripción técnica de Laguna, cataloga como "fríos". Este es un concepto estrictamente médico, que entronca con la tradición humoral galénica, y que Laguna resalta en sus anotaciones. Así, en relación con los procesos judiciales incoados a las brujas, comenta Laguna que preguntadas si habían sentido placer de su relación carnal con el demonio:

"respondieron constantemente que no, y esto a causa de la incomportable frialdad que sentían en las partes diabólicas, de las cuales también a su parecer se les revertía un humor frío como el hielo y a manera de granizo por las entrañas. Los cuales accidentes no pueden proceder de otra causa, sino de la excesiva frialdad del ungüiento, que las traspasa a todas y se les mete en los tuétanos" (p. 422).

Pero la concordancia entre ambos textos no se limita únicamente a la descripción de los efectos farmacológicos de las unturas, sino que continúa en la 
valoración juiciosa del carácter diabólico de estas prácticas. Laguna concluye que:

"todo cuanto dicen y hacen las desventuradas brujas es sueño, causado de brebajes y unciones muy frías, las cuales de tal suerte las corrompen la memoria y la fantasía, que se imaginan las cuitadillas y aun firmísimamente creen haber hecho despiertas todo cuanto soñaron durmiendo" (p. 422).

Este planteamiento también es adoptado por Cervantes, quien en la mencionada novela ejemplar concluye con respecto a la adscripción vulgar de la relación de las pócimas con las prácticas mágicas que "todas estas cosas y las semejantes son embelecos, mentiras" (p. 680).

\title{
Los filtros de amor en El licenciado Vidriera y en El celoso extremeño
}

La elaboración de filtros de amor y pócimas narcóticas con remedios herbales capaces de modificar los sentimientos y la voluntad, en el marco de la tradición popular relacionada con la brujería, también es relatada en algunas obras cervantinas, como en las novelas El licenciado Vidriera y El celoso extremeño, aunque Cervantes se refiere también a estos preparados desde una perspectiva despectiva, a pesar del gran arraigo popular de que gozaban, como se pone de manifiesto en el Quijote: "suelen hacer algunas mujercillas simples y algunos embusteros bellacos, algunas misturas y venenos con que vuelven locos a los hombres" (I, XXII, p. 208). En la primera de la las mencionadas novelas relata Cervantes que:

\begin{abstract}
"aconsejada de una morisca, en un membrillo toledano dio a Tomás unos de estos que llaman hechizos, creyendo que le daba cosa que le forzase la voluntad a quererla: como si hubiese en el mundo yerbas, encantos ni palabras suficientes a forzar el libre albedrío... Comió en tan mal punto Tomás el membrillo, que al momento comenzó a herir de pie y de mano como si tuviera alferecía, y sin volver en sí estuvo muchas horas, al cabo de las cuales volvió como atontado, y dijo con lengua turbada y tartamuda que un membrillo que había comido le había muerto... y aunque le hicieron los remedios posibles, sólo le sanaron la enfermedad del cuerpo, pero no de lo del entendimiento" (p. 587).
\end{abstract}

En la segunda novela, una joven esposa aplica a su anciano marido un ungüento, de tal virtud que:

"untados los pulsos y las sienes con él, causaba un sueño profundo, sin que de él se pudiese despertar en dos días, si no era lavándose con vinagre todas las partes que se habían untado... y asimismo le untó las ventanas de las narices... Poco espacio tardó el alopiado ungüento en dar manifiestas señales de su virtud, porque luego comenzó a dar el viejo tan grandes ronquidos... El ungüento con que estaba untado su señor tenía tal virtud que, fuera de quitar la vida, ponía a un hombre como muerto" (p. 607). 
En este último pasaje, Cervantes utiliza un adjetivo italianizado ("alopiado") para dar cuenta de que el ungüento aplicado por la esposa está elaborado con opio ${ }^{24}$. Según Bucalo (1998), esta acepción, que no encuentra en ningún otro autor español de la época, deriva del término 'alloppiato', que se venía utilizando en Italia desde el siglo XIV para designar aquellas bebidas que contenían derivados opiáceos. La descripción de los efectos del ungüento "alopiado" también concuerda con las descripciones efectuadas por Laguna en su Dioscórides (Tabla I). En relación con el papaver hortense, sobre todo la variedad llamada pithitis o nigrum papaver, Laguna anota que:

\footnotetext{
"dada una onza de simiente a un hombre de complexión delicada, le hará dormir in aeternum... La lecheriza de la simiente... hace dormir gravísimamente... Es tan grande la frialdad del opio que quita el sentido a las partes, y ansí adormenta... En suma, el opio, enemigo del cuerpo humano, es un veneno sabroso, que de nuestro calor natural no puede ser, sino difícilmente, alterado" (p. 415).
}

También se refiere Laguna explícitamente al opio y al meconio (así como a las "medicinas opiatas") en el Libro VI de su obra, correspondiente a los venenos mortíferos: “... dar a beber sin duelo medicinas opiatas... adormece de un tan profundo sueño que no despierta jamás" (p. 586). En este apartado, donde se recogen también las herramientas terapéuticas para el tratamiento de los intoxicados por opio, se recomienda, entre otras alternativas, la aplicación al paciente de vinagre caliente, hecho que coincide de nuevo con el pasaje cervantino.

En cualquier caso, Cervantes, habitualmente, elude dar datos concretos sobre la composición de los preparados de esta naturaleza que cita en sus obras, ni suele especificar ninguno de sus ingredientes, como hemos resaltado, a pesar de indicar su procedencia herbal, debido posiblemente a la precaución que le causaba los efectos censores y punitivos del Tribunal del Santo Oficio. Es más, en su referencia a la composición del ungüento descrito en $E l$ celoso extremeño, el recurso al término italianizado "alopiado" bien podría tratarse de una forma de enmascarar la referencia explícita al opio. Del mismo modo, por la descripción de los síntomas acontecidos a sus personajes, bien pudieran haber sido los ingredientes el beleño o el solano en el caso de $\mathrm{El} \mathrm{co}$ loquio de los perros, o la mandrágora en el caso de El licenciado Vidriera. De la mandrágora dice el Dioscórides que induce "un profundísimo sueño... y tan pertinaz porfía de dormir, que el tal accidente no difiere nada de la letargia" (p. 586).

24. De acuerdo con BuCALo, Maria Grazia "Los italianismos...”, Cervantes recurrió al uso frecuente de italianismos en sus obras, dado su periplo italiano durante su juventud. 


\section{Las pócimas venenosas en La española inglesa}

También en el marco de la brujería con finalidad amatoria recurre Cervantes al empleo de los venenos (Simó, 2005). Así, en La española inglesa, la camarera protestante decide envenenar a Isabela por haber despreciado los amores de su hijo:

"Y fue su determinación matar con tósigo a Isabela;... aquella misma tarde atosigó a Isabela en una conserva que le dio, forzándola que la tomase por ser buena contra las ansias de corazón que sentía... a Isabela se le comenzó a hinchar la lengua y la garganta, y a ponérsele denegridos los labios, y a enronquecérsele la voz, turbársele los ojos y apretársele el pecho: todas conocidas señales de haberle dado veneno" (p. 579).

La acepción "tósigo" procede del latín "tóxicum" y es referida en el Dioscorides como un veneno que inflama la lengua y los labios e induce la locura (Simó, 2005). Aunque los efectos descritos podrían ser causados por diferentes sustancias, como el eléboro negro o el acónito (Aconitum napellus), Laguna describe, de forma muy parecida (Tabla I), los efectos tóxicos inducidos por el beleño:

"a los que tragaron el hyoscyamo blanco sobreviene gran relajación de junturas, apostémaseles la lengua, hínchaseles la boca, inflámaseles y paréceles turbios los ojos, estréchaseles el aliento, acúdeles sordedad con vaguidos de cabeza, y una comezón de las encías, y en todo el cuerpo. Además de esto, embótaseles el sentido, les viene borrachez...” (p. 585).

Del mismo modo, en este pasaje, Cervantes puede tomar también de Laguna algunos remedios terapéuticos supuestamente útiles, procedentes de la medicina medieval aunque aún vigentes en la mentalidad humanista, para el tratamiento de dichos envenenamientos. Según Laguna:

"de todas las medicinas preservativas contra pestilencia y veneno, al cuerno de unicornio se da la gloria primera... Prefiere el conciliador a cualquier otro remedio, el polvo de esmeralda, del cual manda dar dos dramas de vino. Mas esta cura sólo se puede administrar a Pontífices y Emperadores, pues dos dramas de esmeraldas perfectas valen poco menos que dos ciudades" (p. 577).

Por su parte, Cervantes relata que, a Isabela, la reina "hizo dar cantidad de polvos de unicornio, con muchos otros antídotos que los grandes príncipes suelen tener prevenidos para semejantes necesidades" (p. 579). 


\section{A MODO DE CONCLUSIÓN}

La lectura y manejo de diversos tratados médicos, algunos de los cuales parece que integraban la biblioteca particular de Cervantes, podrían haber servido al autor del Quijote para caracterizar, desde la perspectiva médica, a algunos de sus personajes, hecho que ha sido ampliamente discutido, y posiblemente demostrado, en el caso del Examen de ingenios para las ciencias de Huarte de San Juan y Moriae encomium de Erasmo. En relación con la materia terapéutica, el único libro existente en la biblioteca particular de Cervantes era un ejemplar del Dioscórides de Andrés Laguna, único libro de carácter médico que también, curiosamente, cita Cervantes en toda su producción literaria.

En sus obras literarias, Cervantes parece conocer no solo las virtudes de algunas plantas medicinales, sino los diferentes preparados farmacéuticos elaborados con ellas. Nosotros hemos planteado la hipótesis de que algunos de estos conocimientos, amplios en ciertos aspectos, procedieran de la lectura del Dioscórides anotado por Laguna, que pudo servir de fuente documental para sus pasajes médicos. Prueba de ello son las descripciones del efecto de algunas plantas, coincidentes con las aportadas por Laguna, como el caso de los efectos alucinógenos de los ungüentos de brujas y el carácter galénico de "frialdad" de los mismos (El coloquio de los perros) y de las propiedades terapéuticas del romero en el tratamiento de heridas y traumatismos o del (El Quijote) o del uso de una frase literal del médico segoviano, referida al ruibarbo, para narrar la necesidad de Don Quijote de "purgar su exceso de cólera". También describe Cervantes los efectos narcóticos del opio (El celoso extremeño), y, sin citar su composición, los efectos psicodislépticos de de algunos preparados (El licenciado Vidriera), así como de ciertos venenos (La española inglesa), elaborados todos a base de hierbas, que coinciden estrechamente con las descripciones relatadas en algunos capítulos de la obra de Laguna.

Queremos concluir este trabajo destacando que el posible "uso" del Dioscórides de Laguna como herramienta referencial y documental por parte de Cervantes no supone, en nuestra opinión, ninguna merma de la creatividad artística del autor, como se podría pensar desde planteamientos reduccionistas, sino todo lo contrario. La genialidad estriba en saber integrar conocimientos dispersos y darles consistencia y realismo, y si esto es difícil en el marco general de la ciencia (véase la obra del propio Laguna), mucho más lo debe ser en el de la literatura. En este sentido, como auténtico genio, Cervantes trataría de integrar los saberes de la materia médica, que tan familiar le era, en su universo literario, dotando a sus obras de un toque de distinción técnica, a modo de salvas de erudito. Y para lograr este objetivo en los aspectos relativos a la terapéutica, que mejor opción que recurrir a la más prestigiosa de las obras de su tiempo en este campo: el Dioscórides de Andrés Laguna. 


\section{BIBLIOGRAFÍA}

Alonso-Fernández, F., "Dos especies psicopatológicas: Don Quijote y el licenciado Vidriera", Torre de los Lujanes, 25, 2005, 45-64.

Alvar, A., Cervantes. Genio y libertad, Madrid, Temas de Hoy, 2004.

BARANDA, C., "Los lectores del Dioscórides: estrategias discursivas del Doctor Laguna", Criticón, 58, 1993, 17-24.

Bataillon, M., Erasmo y España, México, FCE, 1966.

Batalllon , M., Le Docteur Laguna, auteur du "Voyage en Turquie", Paris, Librairie des Éditions Espagnoles, 1958.

BeÁ, J., HernándeZ, V., "Don Quixote: Freud and Cervantes", International Journal of Psycho Analysis, 65, 1984, 141-153.

Bruneton, J., Farmacognosia. Fotoquímica Plantas Medicinales, $2^{\text {a }}$ edición, Zaragoza, Acribia S.A., 2001.

Bucalo, M. G., "Los italianismos en las "Novelas Ejemplares" de Miguel de Cervantes Saavedra", Cuadernos de Filología Italiana de la Universidad Complutense de Madrid, 5, 1998, 29-80.

CABANÉs, P., "La medicina en la historia medieval cristiana", Espéculo Revista de Estudios Literarios de la Universidad Complutense de Madrid, 2006, revista electrónica, disponible en http://www.ucm.es/info/especulo/numero32/medicime.html, fecha de acceso 20/11/2006.

Canavagio, J., Cervantes. En busca del perfil perdido, $2^{\text {a }}$ edición, Madrid, Espasa-Calpe, 1992.

Caro Baroja, J., Las brujas y su mundo, Madrid, Alianza Editorial, 1990.

CASTRo, A., El pensamiento de Cervantes, Madrid, Trotta, 2002.

Centro Virtual Cervantes, Instituto Cervantes, 2000-2005, disponible en http://cvc. cervantes.es, fecha de acceso 03/08/2005.

Cervantes, M., Obras completas, edición de Florencio Sevilla, Madrid, Editorial Castalia, 1999.

ChiAPPo, L., "La última melancolía de Alonso Quijano, el Bueno", Actas de Psiquiatría y Psicología de América Latina, 40, 1994, 69-76.

Dubler, C. E., La Materia Medica de Dioscórides. Transmisión medieval y renacentista, Barcelona, Tipografía Emporium, 1953-1959.

EISENBERG, D., La biblioteca de Cervantes. Una reconstrucción, 2002, disponible en http://bigfoot.com/ daniel.eisenberg, fecha de acceso 27/10/2006.

EsteVA De SAGRera, J., "La farmacia en el Quijote", OFFARM, 24, 2005, 104-116.

Font Quer, P., Plantas Medicinales. El Dioscórides renovado, $5^{\text {a }}$ edición, Barcelona, Ediciones Península, 2003.

Foust, C. M., Rhubarb: The wondrous drug, Princeton, University Press, 1992.

Fraile, J. R., De Miguel, A., Yuste, A., "El dolor agudo en El Quijote". Revista Española de Anestesiología y Reanimación, 50, 2003, 346-355.

García Barreno, P., "La medicina en El Quijote y en su entorno", en La ciencia y El Quijote, Sánchez Ron, J. M., director, Barcelona, Crítica S.L., 2005, 155-179.

GonzÁlez Manjarrés, M. A., Entre la imitación y el plagio. Fuentes e influencias en el Dioscórides de Andrés Laguna, Segovia, Obra Social y Cultural de Caja Segovia, 2000.

HARNER, M. J., "The role of hallucinogenic plants in European witchcraft", en Hallucinogens and Shamanism, Harner, M. J, editor, Londres, Oxford University Press, 1973, 124-150.

Hernando, T., "Vida y labor médica del doctor Andrés Laguna", en Vida y Obra del Dr. Andrés Laguna, Sánchez Granjel, L., editor, Salamanca, Consejería de Cultura de la Junta de Castilla y León, 1990, 81-204. 
Iranzo, A., Santamaría, J., Riquer, M., "Sleep and sleep disorders in Don Quixote”, Sleep Medicine, 5, 2004, 97-100.

Laguna, A., Pedacio Dioscórides Anazarbeo, acerca de la materia medicinal, y de los venenos mortiferos, Salamanca, Mathias Gast, 1563.

LóPEz, A., Molimientos, puñadas y caídas acaecidos en el Quijote, Alcalá de Henares, Editorial de la Universidad de Alcalá, 1996.

LóPEz, H., "La medicina en el Quijote", Actas Luso-Españolas de Psiquiatría y Neurología, 30, 1971, 35-44.

LóPez-Muñoz, F., Alamo, C., Cuenca, E., "Historia de la Psicofarmacología”, en Tratado de Psiquiatría, tomo II, Vallejo, J., Leal, C., directores, Barcelona, Ars Medica, 2005, 1709-1736.

LÓPEZ-MuÑoZ, F., AlAMO, C., GARCÍA-GARCÍA, P., "The herbs that have the property of healing...”: The phytotherapy in Don Quixote”, Journal of Ethnopharmacology, 106, 2006a, 429-441.

LóPez-Muñoz, F., Rubio, G., Alamo, C., García-García, P., "A propósito de la locura del hidalgo Alonso Quijano en el marco de la medicina española tardorrenacentista", Anales de Psiquiatría, 22, 2006b, 133-145.

Martín-Araguz, A., Bustamante-Martínez, C., "Examen de ingenios, de Juan Huarte de San Juan, y los albores de la Neurobiología de la inteligencia en el Renacimiento español", Revista de Neurología, 38, 2004, 1176-1185.

Montes-Santiago, J., "Miguel de Cervantes: saberes médicos, enfermedades y muerte", Anales de Medicina Interna (Madrid), 22, 2005, 293-297.

MontIEL, L., "La medicina de la mente en el periodo moderno", en Historia de la Neuropsicofarmacología. Una nueva aportación a la terapéutica farmacológica de los trastornos del Sistema Nervioso Central, López-Muñoz, F., Alamo, C., editores, Madrid, Ediciones Eurobook S.L., 1998, 39-50.

MoRALEs, R., Flora literaria del Quijote. Alusiones al mundo vegetal en las obras completas de Cervantes, Albacete, Instituto de Estudios Albacetenses "Don Juan Manuel", 2005.

Munguía, V. E., Biografía de Miguel de Cervantes Saavedra: Estado de la cuestión, Madrid, Servicio de Publicaciones de la Universidad Complutense, 1995.

NoRTON, S., "Experimental Therapeutics in the Renaissance", Journal of Pharmacology and Experimental Therapy 304, 2003, 489-492.

Osterc, L., "Cervantes y la medicina", Verba Hispanica, 6, 1996, 17-22.

PARDo TOMÁs, J., "Andrés Laguna y la medicina europea del Renacimiento", ciclo de Conferencias Los orígenes de la ciencia moderna, La Orotava y Las Palmas de Gran Canaria, 21-22 de octubre de 2002, disponible en http://www.nti.educa.rcanaria.es/fundoro/ act11 12pdf web/capitulos/02.pdf, fecha de acceso 20/11/2006.

Peleg, R., TAndeter, H., Peleg, A., "The medical Cervantes" Canadial Medical Association Journal, 165, 2001, 1623-1624.

PeÑA, S., "La locura del Quijote", Revista Médica de Chile, 127, 1999, 89-93.

Postel, J., Quétel, C., Historia de la psiquiatría, México, Fondo de Cultura Económica, 1987, 116-122.

Prieto, J. M., "El Bálsamo de Fierabrás", Boletín Latinoamericano y del Caribe de Plantas Medicinales y Aromáticas, 4 (3), 2005, 48-51

PUERTO, F. J., "La terapéutica y la farmacia durante el Barroco", en El mito de panacea. Compendio de Historia de la Terapéutica y de la Farmacia, Puerto, F. J., editor, Madrid, Ediciones Doce Calles, 1997, 229-383.

Puerto, J., La fuerza de Fierabrás. Medicina, ciencia y terapéutica en tiempos del Quijote, Madrid, Editorial Just in Time S.L., 2005a.

Puerto, J., "La Materia Medicinal de Dioscórides, Andrés Laguna y El Quijote", en La ciencia y El Quijote, Sánchez Ron, J. M., director, Barcelona, Crítica S.L., 2005b, 141-154. 
Reverte Coma, J.M., "Antropología médica del Quijote. Farmacopea en el Quijote”, Previsión Sanitaria Nacional, 76, 1992, 38-44, texto modificado disponible en http://www.icm.es/info/museoafc/home.html, fecha de acceso 27-10-2006.

RIDDLe, M., Dioscorides on Pharmacy and Medicine, Austin, University of Texas Press, 1985.

Rojo VeGa, A., "Erasmismo tardío en la medicina española del siglo XVII: Antonio Ponce de Santa Cruz", Investigación Histórica (Valladolid), 4, 1983, 85-97.

Rothman, T., "De Laguna's commentaries on hallucinogenic drugs and witchcraft in Dioscorides' Materia Medica", Bulletin of History of Medicine, 46, 1972, 562-567.

Salillas, R., Un gran inspirador de Cervantes. El doctor Juan Huarte y su "Examen de Ingenios”, Madrid, Librería de V. Suárez, 1905.

SÁnchez Granjel, L., "El médico Andrés Laguna", en Andrés Laguna. Humanismo, ciencia y política en la Europa Renacentista, García Hourcada, J. L, Moreno Yuste, J. M., coordinadores, Valladolid, Junta de Castilla y León, 2001, 11-22.

SÁnchez Grangel, L., "Lectura médica de El Quijote", en III y IV Centenario de El Quijote en la Real Academia Nacional de Medicina, Madrid, Editorial Real Academia Nacional de Medicina, 2005, 159-173.

SAURI, J. J., Historia de las ideas psiquiátricas, Buenos Aires, Ediciones Carlos Lohle, 1969.

Simó, L., "Los "tósigos de amor" en las novelas de Cervantes", Espéculo Revista de Estudios Literarios de la Universidad Complutense de Madrid, 2005, disponible en http://www.ucm.es/info/especulo/numero29/tosigos.htlm, fecha de acceso 27/10/2006.

Ungerer, G., "George Baker: translator of Aparicio de Zubia's pamphlet on the "Oleum Magistrale", Medical History, 30, 1986, 203-211.

VAlle, A., "Botica y farmacia en el Quijote", Anales de la Real Academia Nacional de Farmacia, 68, 2002, 693-734.

Vilanova, A., Erasmo y Cervantes, Barcelona, CSIC, 1949.

VIllamil, I., VIlacián, M. J., "Cervantes, El Quijote y la medicina", Revista Médica de Chile, 133, 2005,1258-1260.

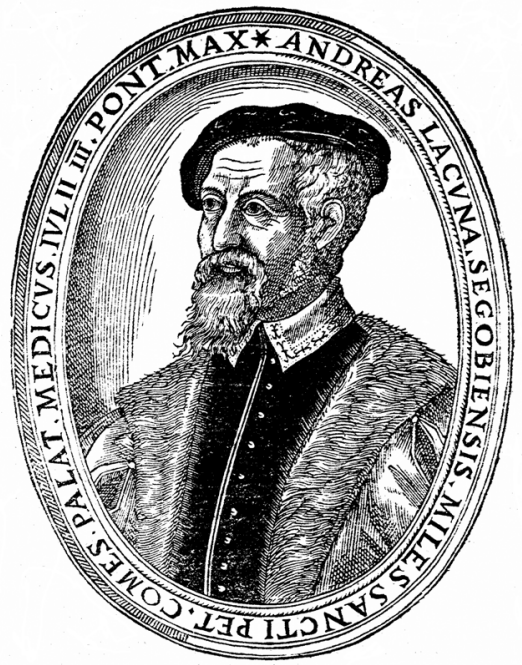

Figura 1: Retrato de Andrés Laguna, según un grabado publicado en la edición de su Dioscórides de 1563, realizada en la imprenta salmantina de Mathías Gast. 


\title{
Resumen
}

La obra literaria de Miguel de Cervantes ha sido ampliamente estudiada desde numerosos puntos de vista, incluida la perspectiva médica. En el presente trabajo defendemos la hipótesis de que el Dioscórides de Andrés Laguna fuese la fuente utilizada por Cervantes en sus pasajes literarios relativos a aspectos terapéuticos, sobre todo en relación con las plantas dotadas de virtudes medicinales. Esta obra, existente en la biblioteca particular de Cervantes, es el único libro de carácter médico citado por el literato en toda su producción (El Quijote). Además de las plantas medicinales citadas en sus obras, de las que hemos identificado la achicoria, adelfa, beleño, opio, romero, ruibarbo, tabaco, tamarisco, tártago y verbena, Cervantes también parece conocer los efectos de diferentes preparados farmacéuticos elaborados a base de plantas medicinales (ungüento blanco, aceite de Aparicio, filtros narcóticos, etc.). Nuestra hipótesis se justifica en el empleo, por parte de Cervantes, de descripciones similares a las aportadas por Laguna en su Dioscorides (los efectos alucinógenos de los ungüentos de brujas en El coloquio de los perros, las propiedades terapéuticas del romero en el tratamiento de heridas y traumatismos en el Quijote, los efectos narcóticos del opio en El celoso extremeño, los efectos psicodislépticos de algunos filtros de amor en El licenciado Vidriera, los efectos tóxicos de algunos venenos en La española inglesa), e incluso, en algún caso, de citas casi literales de los comentarios de Laguna (el efecto purgante del exceso de cólera del romero en el Quijote).

Palabras clave: Cervantes. Dioscórides. Laguna. Locura. Farmacología. Historia de la Medicina. Terapéutica.

\begin{abstract}
The literary works of Miguel de Cervantes have been widely studied from numerous points of view, including the medical one. In the present work, we defend the hypothesis that the Andrés Laguna version of Dioscorides was the source used by Cervantes in his literary passages related to therapeutic aspects, especially in relation to plants with medicinal properties. This book, a copy of which was in Cervantes' private library, is the only medical treatise cited by the novelist in any of his writings (Don Quixote). Apart from the medicinal plants mentioned in his works, of which we have identified chicory, oleander, henbane, opium poppy, rosemary, rhubarb, tobacco, tamarisk, seeds of spurge, and vervain, Cervantes also seemed familiar with the effects of different pharmaceutical preparations produced from plants (white ointment, Aparicio's Oil, narcotic powders, etc.). Our hypothesis is backed up by Cervantes' use of descriptions similar to those of Laguna in his Dioscorides (the hallucinogenic effects of witches' ointments in The Colloquy of the Dogs, the therapeutic properties of rosemary in the treatment of wounds and traumatisms in Don Quixote, the narcotic effects of opium in The Jealous Extremaduran, the psychodysleptic effects of some love potions in The Licentiate of Glass, or the toxic effects of some poisons in The Spanish-English Lady), and even, in some cases, by use of Laguna's similar quotations (as in his reference to the purging of excessive bile in Don Quixote).
\end{abstract}

Key words: Cervantes. Dioscorides. Laguna. Madness. Pharmacology. History of Medicine. Therapeutics. 